\title{
Prophylactic or Simultaneous Administration of Recombinant Human Granulocyte Colony Stimulating Factor in the Treatment of Group B Streptococcal Sepsis in Neonatal Rats ${ }^{1}$
}

\author{
MITCHELL S. CAIRO, DEBORAH MAUSS, SUMITHRA KOMMAREDDY, KAROL NORRIS, \\ CARMELLA VAN DE VEN, AND HOUCHANG MODANLOU \\ Division of Hematology/Oncology, Childrens Hospital of Orange County, Orange, California 92668; Division of \\ Neonatology, Miller Children's Hospital, Long Beach, California 90801; and University of California, Irvine, \\ Orange, California 92668
}

\begin{abstract}
Despite the emergence of newer antibiotic treatments, group B streptococcal infection still carries a high mortality rate in the newborn and is characterized by reduced neutrophil proliferative pools, neutrophil storage pools, neutropenia, and polymorphonuclear cell dysfunction. Recombinant human granulocyte-colony stimulating factor (rhG-CSF) has recently been demonstrated to induce neutrophilia and modulate neutrophil proliferative pools and neutrophil storage pools in the newborn rat. We therefore investigated the adjuvant effect of rhG-CSF given to group B streptococcus (GBS) septic Sprague-Dawley newborn $(<36 \mathrm{~h})$ rats treated with and without antibiotic therapy. After inoculation of GBS, a GBS survival curve established the $\mathrm{LD}_{50}$ at $50 \mathrm{~h}$ to be approximately $3 \times 10^{6}$ organisms/gm. Newborn rats were divided into four treatment groups after GBS inoculation. rhG-CSF was administered at the same time as GBS inoculation. At $24 \mathrm{~h}$, there was approximately $100 \%$ survival in all groups. However, by $72 \mathrm{~h}$ after GBS inoculation, there was a significant difference in survival. Group 1, PBS/Alb, had a survival rate of $4 \%$; group 2 , rhG-CSF, 9\%; group 3, antibiotics, $28 \%$; and group 4 , antibiotics plus rhG-CSF, $91 \%$ ( $p \leq$ 0.001 ). Additionally, when rhG-CSF was administered prophylactically ( $6 \mathrm{~h}$ before GBS), a similar significant synergistic effect in survival was demonstrated with granulocyte colony stimulating factor plus antibiotics versus antibiotics alone $(70$ versus $10 \%)(p \leq 0.01)$. These preliminary data suggest that either simultaneous or prophylactic pulse administration of rhG-CSF may have a synergistic and protective effect on survival in antibiotic-treated experimental GBS in the neonatal rat. (Pediatr Res 27: 612-616, 1990)
\end{abstract}

\section{Abbreviations}

GBS, group B streptococcus

CSF, colony stimulating factor

G-CSF, granulocyte-colony stimulating factor

rhG-CSF, recombinant human granulocyte-colony stimulating factor

PMN, polymorphonuclear cell

Received August 30, 1989; accepted February 8, 1990.

Correspondence and reprints requests: Mitchell S. Cairo, M.D., Associate Director, Hematology/Oncology, Research Director, Cancer and Bone Marrow Transplantation, Childrens Hospital of Orange County, 455 S. Main, Orange, CA 92668.

Supported by grants from the Pediatric Cancer Research Foundation, Memorial Hospital Research Foundation, and PPP Foundation. DC.

'Presented in part at the Society of Pediatric Research, May 1989, Washington,
NSP, neutrophil storage pool

i.p., intraperitoneal(ly)

The incidence of neonatal sepsis has been estimated to occur in approximately one to 10 patients per 1000 live births (1). The most common organism associated with overwhelming sepsis in both preterm and term newborns is GBS. GBS may manifest itself under two different clinical presentations: early and late onset (2). Despite the recent emergence of the modern antibiotic era and the use of aggressive cardiopulmonary supportive therapy, the overall mortality from GBS sepsis still remains significant. Although a number of factors are responsible for the high incidence and mortality rate associated with bacterial sepsis in the newborn, a developmental immaturity in neonatal host defense remains as one of the most important barriers to improving the mortality rate associated with this disorder (3). One of the most important deficits associated with the increased risk of bacterial sepsis is quantitative and qualitative deficiency of the neonatal phagocytic system (4).

Experimental GBS in neonatal Sprague-Dawley rats have previously demonstrated a high mortality rate and an association with exhaustion of mature NSP from neonatal rat bone marrow (5). Experimental studies in this animal model have demonstrated that profound peripheral neutropenia and depletion of NSP cells almost always precede death and appear to be correlated with the high mortality rate (6). Altered granulopoiesis in the premature and term newborn rat are the major factors in predisposing newborn rats to an increase in morbidity and mortality during experimental bacterial infection (7-9). Human studies of neonatal sepsis have also demonstrated an association with peripheral neutropenia (8). Additionally, the mortality rate associated with bacterial sepsis in humans is also higher in newborns presenting with peripheral neutropenia than in neonates with normal or increased neutrophil counts (3).

Myeloid progenitor cell proliferation and maturation and mature granulocyte bone marrow egress are dependent on the continuous supply of hematopoietic CSF. CSF are comprised of a variety of glycoproteins with biologic specificities defined by their ability to stimulate proliferation and differentiation of hematopoietic stem cells of various lineages. G-CSF, purified to homogeneity from the human bladder carcinoma cell line 5637 , is one such glycoprotein (10). G-CSF has been administered to various animals and induces early peripheral neutrophilia. The acute neutrophilia induced by G-CSF is presumed to be secondary to egress of NSP cells from animal bone marrows (11-13). 
Human G-CSF also appears to not only regulate late hemotopoietic neutrophil progenitor cell proliferation and release but also enhance mature neutrophil physiologic function $(14,15)$.

We have previously demonstrated that i.p. administration of rhG-CSF to neonatal rats induces early neutrophilia and expansion of the neutrophil proliferative pool $(16,17)$. The increased morbidity and mortality of bacterial sepsis in the neonate is in part secondary to altered myelopoiesis and a tendency to peripheral neutropenia. We postulated that prophylactic or simultaneously administered human rhG-CSF could possibly enhance neonatal host defense and subsequently modify the high mortality rate associated with experimental group B streptococcal infection. Our study investigated the adjuvant use of this hematopoietic growth factor (with and without antibiotics) under experimental conditions of group B streptococcal infection in newborn Sprague-Dawley rats.

\section{MATERIALS AND METHODS}

$G$-CSF. rhG-CSF was purchased from Amgen Biologicals (Thousand Oaks, CA), and was prepared from an E. coli host recombinant DNA procedure to $95 \%$ purity before formulation in $0.025 \%$ HSA. SDS gel electrophoresis was used to confirm the purity of the growth factor by the appearance of a single protein band. Biologic activity of $2 \times 10^{8} \mathrm{IU} / \mathrm{mg}$ was determined by granulocyte colony formation on human nonadherent bone marrow cells in semisolid media. The Limulus amebocyte lysate assay was used to demonstrate the absence of measurable endotoxin. Purified G-CSF was used at concentrations of $5.0 \mu \mathrm{g} / \mathrm{kg}$ [diluted with PBS pH 7.4, and HSA (Alpha Therapeutic Corp., Los Angeles, CA)] (16).

Organism: GBS. GBS, type III, N-strain, was used in our study. The organism was isolated from an infected neonate and serotyped by the precipitin method using rabbit antisera. The organism was grown in Todd Hewitt broth to logarithmic phase and then aliquoted and stored at $-70^{\circ} \mathrm{C}$ until use. Aliquots were thawed and allowed to grow to maximum phase growth $(6 \mathrm{~h})$ in fresh Todd-Hewitt broth. Organisms were then sedimented by centrifugation and washed three times in sterile PBS. Concentration of bacteria was standardized by its OD at $620 \mathrm{~nm}$, and a suspension of $3 \times 10^{6}$ organisms $/ \mathrm{g}$ body wt $/ 100 \mu \mathrm{L}$ was prepared for injection.

Animal inoculation. Litters of albino Sprague Dawley neonatal rats (Bantin-Kingman Laboratories, Fremont, CA) $\leq 24$ h old $(6-8 \mathrm{~g})$ were used in this study. Mothers of the litters were received $1 \mathrm{wk}$ before delivery, and were housed at the vivarium at the University of California Irvine Medical Center. They were maintained at constant room temperature, with water and rodent feed (Purina Chow, Ralston-Purina, Co., St. Louis, MO) ad libitum. Approval for this study was granted by the Animal Use Committee at UCI. Before inoculation of the neonatal rat, the site of injection was washed with Betadine solution (povidoneiodine, $10 \%$, Purdue Frederick, Norwalk, CT). Intraperitoneal injections of rhG-CSF were accomplished with a sterile tuberculin syringe fitted with a 27.5-gauge needle. Antibiotics were administered by intramuscular injection at the hind leg. GBS was injected s.c. at the tail region of the animal with a sterile tuberculin syringe.

Treatment. The $\mathrm{LD}_{50}$ of GBS at $48 \mathrm{~h}$ and the $\mathrm{LD}_{90}$ at $72 \mathrm{~h}$ was determined by injecting neonatal rats as described with concentrations of $3 \times 10^{5}, 3 \times 10^{6}, 3 \times 10^{7}$ bacteria per $g$ wt. To determine the effect of rhG-CSF on peripheral neutrophilia, litters were injected with i.p. rhG-CSF $(5.0 \mu \mathrm{g} / \mathrm{kg})$, or PBS/ $0.025 \%$ HSA i.p. as a control. To determine the rhG-CSF effect on the modulation of neonatal rat GBS sepsis, litters were each given one of several forms of therapy. In the simultaneous studies: 1) rhG-CSF, administered i.p. at $5.0 \mu \mathrm{g} / \mathrm{kg}$ simultaneously with inoculation of GBS; 2) PBS $/ 0.025 \%$ HSA administered i.p. simultaneously with infection of GBS; 3) antibiotics, ampicillin (Bristol Laboratories, Evansville, IN) $150 \mathrm{mg} / \mathrm{kg} / \mathrm{d}$, and gentamicin (Elkins-Sinn, Cherry HIll, NJ), $6.5 \mathrm{mg} / \mathrm{kg} / \mathrm{d}$ intramuscularly q $12 \mathrm{~h}$, started $24 \mathrm{~h}$ after infection with GBS; and 4) rhG-CSF i.p. and antibiotic administration. In the prophylactic studies, the groups consisted of the following: 1) rhG-CSF administered i.p. $6 \mathrm{~h}$ before infection with GBS; 2) rhG-CSF administered i.p. $6 \mathrm{~h}$ before infection with GBS, and antibiotics, ampicillin, and gentamicin started $18 \mathrm{~h}$ after GBS inoculation as described above; 3) PBS/0.025\% HSA administered i.p. 6 h before infection; and 4) PBS $/ 0.025 \%$ HSA administered i.p. $6 \mathrm{~h}$ before GBS infection and antibiotic therapy $18 \mathrm{~h}$ after GBS inoculation.

Mortality and morbidity were monitored, as well as peripheral blood counts, and absolute neutrophil counts as described below.

Quantification of circulating and storage neutrophils. Blood samples were obtained by nicking the jugular vein with a sterile scalpel, and $10 \mu \mathrm{L}$ of free flowing blood was collected. Samples were electronically counted (Serano-Baker Diagnostics, Allentown, PA), and blood smears were prepared, stained with Wright stain, and a 100-200 cell differential was performed. Absolute neutrophil counts were determined by the multiplication of the nucleated cell count by the percentage of neutrophils in the differentials.

Statistical analysis. All results are expressed as mean values \pm SEM of eight to 15 animals, or three to five replicates of blood or bone marrow samples. The probability of significant differences when comparing two treated groups was determined with the use of the unpaired $t$ test, whereas the probability of significant differences when examining multiple treatments was determined by using the analysis of variance followed by the StudentNewman-Keuls multiple range tests to define the unique subsets within the study. Statistical analyses were performed using the Biostat I statistical program (Sigma Soft, Placentia, CA) for the IBM personal computer. Resulting $p$ values $\geq 0.05$ are considered significant.

\section{RESULTS}

$\mathrm{LD}_{50}$ and $\mathrm{LD}_{90}$ were established by s.c. inoculation of $0.1 \mathrm{~mL}$ suspension of type III GBS/g body wt to litters of SpragueDawley newborn rats (Fig. 1). Three $\times 10^{6}$ colony forming units/ $\mathrm{g}$ of GBS type III N-strain resulted in greater than $50 \%$ and $90 \%$ mortality at 48 and $72 \mathrm{~h}$, respectively, after administration. These experiments suggested that $3 \times 10^{6}$ colony forming units/g of GBS would be the most ideal concentration to be used in subsequent studies.

We administered $5 \mu \mathrm{g} / \mathrm{kg}$ i.p. rhG-CSF to newborn pups and determined its effect on peripheral neutrophilia. When i.p. rhGCSF $(5 \mu \mathrm{g} / \mathrm{kg})$ was administered to newborn rats, it resulted in significant neutrophilia within $6 \mathrm{~h}$ of administration and resulted in a prolonged sustained neutrophilia $24 \mathrm{~h}$ after administration (Fig. 2). rhG-CSF administered by i.p. injection resulted in a 3

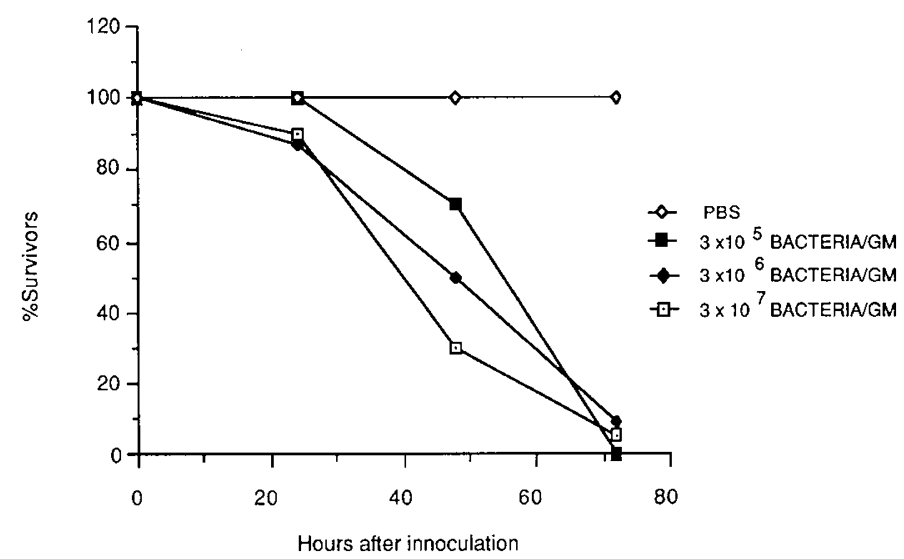

Fig. 1. Survival curves (\% survival) for groups of 20 or more neonatal rats after s.c. injection with type III group B streptococcus. 


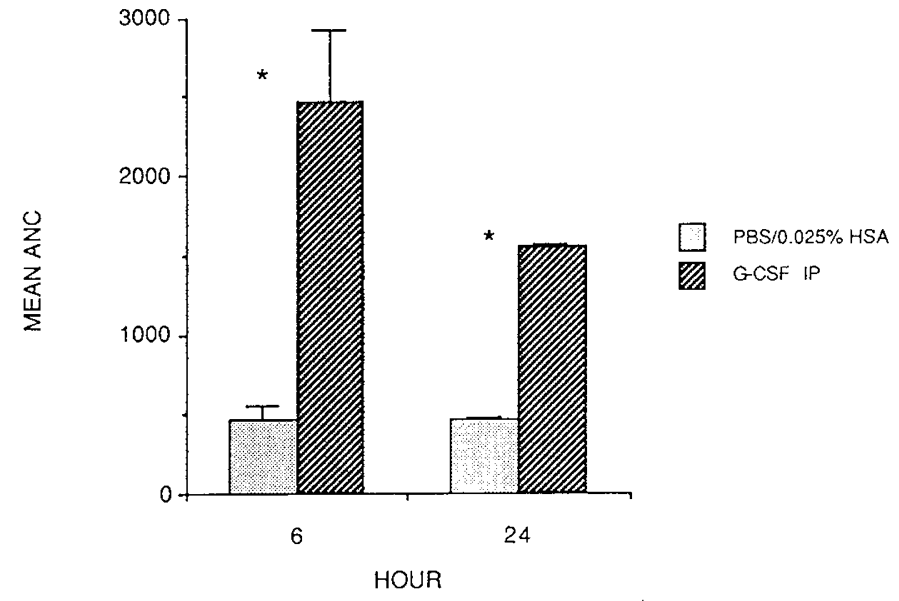

Fig. 2. Comparison of mean absolute neutrophil counts between rhGCSF $(5 \mu \mathrm{g} / \mathrm{kg})$ and PBS $/ 0.025 \%$ HSA at 6 and $24 \mathrm{~h}$ after i.p. injections in groups of 30 or more neonatal rats. ${ }^{*} p \leq 0.001$.

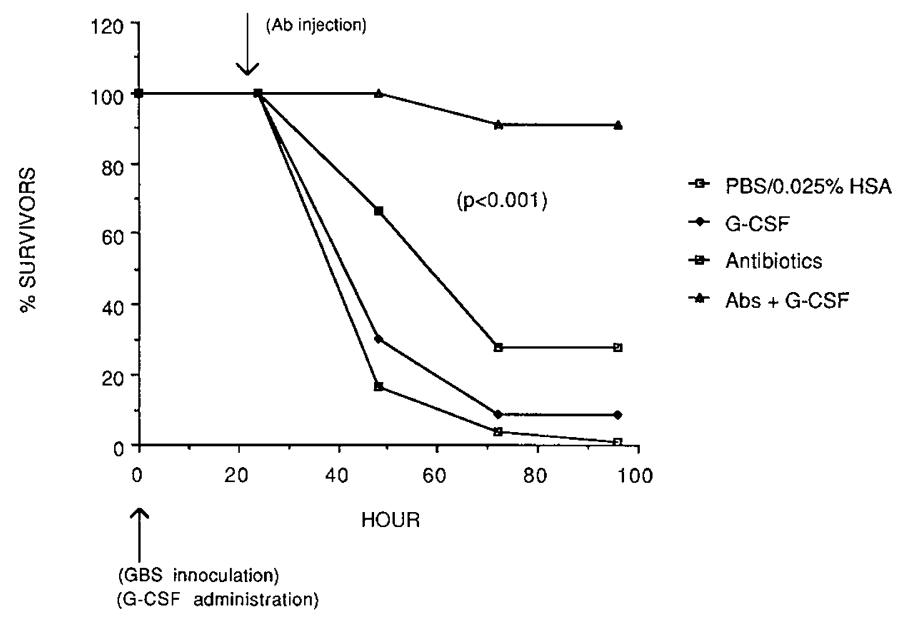

Fig. 3. Percent survival for groups of 20 or more neonatal rats from litters of eight to 10 animals from two to three separate experiments after s.c. injection with GBS at $3 \times 10^{6}$ colonies/g body wt and adjuvant therapy. Adjuvant therapy at h 0 included either i.p. rhG-CSF $(5 \mu \mathrm{g} / \mathrm{kg})$ or PBS $/ 0.025 \%$ HSA. Additionally, antibiotics (Abs) (gentamicin, 6.5 $\mathrm{mg} / \mathrm{kg} / \mathrm{d}$, and ampicillin, $150 \mathrm{mg} / \mathrm{kg} / \mathrm{d}$ ) were administered intramuscularly $24 \mathrm{~h}$ after GBS to the last two groups. $p<0.001$ reflects comparison between $91 \%$ survival in G-CSF and Abs vs Abs alone (72 h).

to 4-fold increase in the peripheral neutrophil count at $6 \mathrm{~h}$ and an almost 1.5 - to 2-fold sustained increase in the circulating absolute neutrophil count by $24 \mathrm{~h}$ (Fig. 2).

Next, litters of 10-11 newborn rats were inoculated s.c. with 3 $\times 10^{6} \mathrm{GBS} / \mathrm{g}$ body wt and randomized to one of four treatment groups. The first group of animals received GBS and PBS/ $0.025 \%$ HSA. Group 2 received GBS and simultaneously received $5 \mu \mathrm{g} / \mathrm{kg}$ i.p. rhG-CSF. Group 3 were inoculated with GBS and within $24 \mathrm{~h}$ of administration of GBS, were also treated with ampicillin and gentamicin. Lastly, group 4 animals were inoculated with GBS and simultaneously were given i.p. rhG-CSF (5 $\mu \mathrm{g} / \mathrm{kg}$ ) and within $24 \mathrm{~h}$ were given similar doses of ampicillin and gentamicin. At $24 \mathrm{~h}$, there was almost $100 \%$ survival in all groups (Fig. 3). By $72 \mathrm{~h}$, however, there was a significant difference in survival among treatment groups. In group 1, the control group, there was only a $4 \%$ survival rate (one of 24 ); in group 2 , which received i.p. rhG-CSF, there was only a $9 \%$ survival rate (two of 23); in group 3, which received antibiotics alone, there was a $28 \%$ survival rate (six of 21 ); but, in group 4 , there was a significant increase in survival rate $(91 \%)$ in animals receiving both antibiotics and i.p. rhG-CSF (19 of 21) ( $p \leq 0.001)$ (Fig. 3).
To assess whether prophylactic administration of i.p. G-CSF could modulate GBS infection in neonatal rats, we chose a different treatment schema for the following experiments. Litters of 10-11 animals were treated under the following conditions. At $\mathrm{h} 0$, i.p. rhG-CSF $(5 \mu \mathrm{g} / \mathrm{kg})$ was given to the first two groups of animals and the 3rd and 4th group received PBS $/ 0.025 \%$ BSA. At h 6, GBS was administered to all four groups. Eighteen $\mathrm{h}$ after administration of GBS, group 2 and group 3 animals were given ampicillin and gentamicin. Group 4 only received $\mathrm{PBS} / 0.025 \% \mathrm{HSA}$ at $\mathrm{h} 0$. The results of these experiments are illustrated in Figure 4. In the animals who were given prophylactic i.p. rhG-CSF followed with antibiotic administration $18 \mathrm{~h}$ later, there was a significant increase in survival at $60 \mathrm{~h}$ compared with the other three treatment groups, resulting in a survival rate of approximately $70 \%(p \leq 0.001)$.

\section{DISCUSSION}

The immaturity of neonatal neutrophil host defense contributes significantly to the high incidence of overwhelming bacterial sepsis in the preterm and term newborn (3). Because neonatal rat bone marrow myeloid proliferative pools are reduced to 10 $20 \%$ of normal adult animal levels and are proliferating at $75-$ $80 \%$ of maximal levels, and because bone marrow NSP are reduced to approximately $25 \%$ of adult levels in term neonatal rats, the neonatal rat is unable to respond efficiently to overwhelming GBS infection $(8,9)$. This ineffective myeloid proliferation and egress response results in an overwhelming tendency to peripheral neutropenia and a high incidence of morbidity and mortality. Additionally, even adequate numbers of circulating PMN during neonatal sepsis may be insufficient to defend against overwhelming bacterial infection because their ability to function normally may be impaired (18).

rhG-CSF cDNA has a 60-70\% homology in nucleotide sequence in the protein coded region with murine G-CSF cDNA and has species crossreactivity (19). Recently, large quantities of mature human G-CSF have been produced by recombinant techniques in $E$. coli $(20)$. rhG-CSF has been demonstrated to induce neutrophilia within $48 \mathrm{~h}$ in adult mice (11), after autologous bone marrow transplantation in primates (12), and after high-dose chemotherapy in transitional cell carcinoma (21). Specifically, rhG-CSF has shortened the period of neutropenia in cynomolgus monkeys after high-dose cyclophosphamide (22),

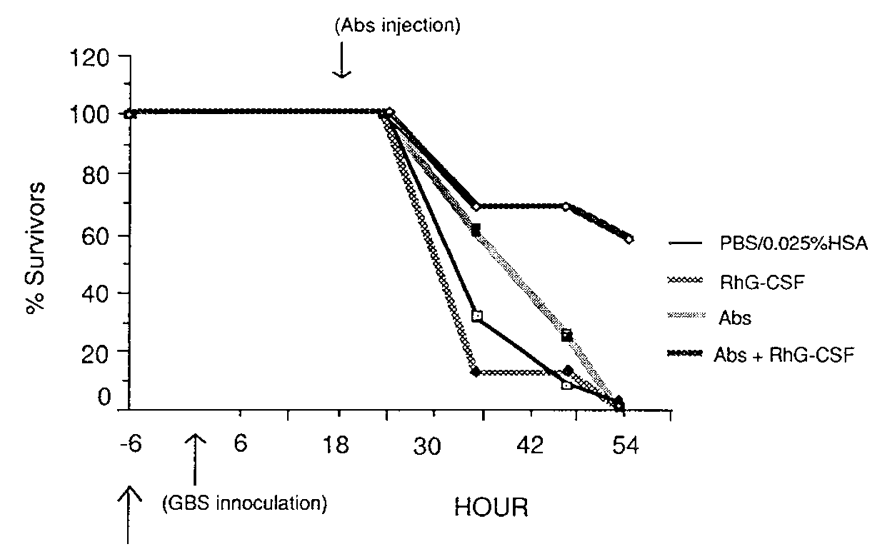

(RhG-CSF administration)

Fig. 4. Percent survival after i.p. injection of $\mathrm{rhG}-\mathrm{CSF}(5 \mu \mathrm{g} / \mathrm{kg})$ or PBS $/ 0.025 \%$ HSA $6 \mathrm{~h}$ before inoculation with GBS $\left(3 \times 10^{6}\right.$ colonies $/ \mathrm{g}$ body wt). Antibiotics (Abs) (gentamicin, $6.5 \mathrm{mg} / \mathrm{kg} / \mathrm{d}$, and ampicillin, $150 \mathrm{mg} / \mathrm{kg} / \mathrm{d}$ ) were started $18 \mathrm{~h}$ after GBS infection. At $24 \mathrm{~h}, 15$ of 24 animals given PBS $/ 0.25 \%$ HSA, 19 of 21 given antibiotics, 18 of 23 given rhG-CSF, and 23 of 23 given rhG-CSF and antibiotics were alive. Percent survival shown in the graph is calculated only from animals surviving at 24 h. $p \leq 0.001$ reflects comparison of prophylactic G-CSF and Abs vs Abs alone. 
busulfan (23), or total body radiation and autologous bone marrow reconstitution (24). Recently, rhG-CSF has been successfully used to treat patients with congenital agranulocytosis (Kostmann's Syndrome) (25) and cyclic neutropenia (cyclic hematopoiesis) (26).

Previously, we have demonstrated that pulse administration of rhG-CSF can induce an early and somewhat sustained neutrophilia in the neonatal rat $(16,17)$. In this study, we investigated the adjuvant effect of administering rhG-CSF to antibiotictreated GBS-infected neonatal rats. When i.p. rhG-CSF was administered simultaneously at the time of inoculation of GBS, we found a significant increase in survival of the antibiotictreated group of animals compared with all other groups.

It is of interest but not too surprising that i.p. rhG-CSF treatment alone without additional antibiotic therapy had no additive effect in the reduction of mortality. With only a singlepulse administration of a CSF, it is unlikely that a transient rise in the neutrophil count can prevent the mortality associated with overwhelming infection with such organisms as GBS without additional antibiotic therapy.

After observing the significant increase in survival with the combination of i.p. rhG-CSF and antibiotics, we next evaluated whether i.p. rhG-CSF could be efficacious if given prophylactically before inoculating newborn rats with GBS. We therefore administered i.p. rhG-CSF $6 \mathrm{~h}$ before the administration of GBS to take advantage of the marked and significant neutrophilia that occurs within $6 \mathrm{~h}$ after rhG-CSF administration. Again, in this experimental model, we found that prophylactic i.p. rhG-CSF, when administered $6 \mathrm{~h}$ before GBS inoculation, also demonstrated a significant synergistic effect in survival with antibiotic therapy versus antibiotics alone. Thus, simultaneous and prophylactic i.p. rhG-CSF resulted in a significant synergistic response with antibiotic therapy compared with antibiotic therapy alone.

Other investigators have examined the effect of human CSF in modulating microbial infection in neutropenic animals. Matsumoto et al. (27) administered high-dose cyclophosphamide to adult mice and randomized mice to receive s.c. rhG-CSF $1 \mathrm{~d}$ after cyclophosphamide therapy. In mice receiving no adjuvant CSF therapy, profound neutropenia developed within $4 \mathrm{~d}$, whereas the animals receiving daily rhG-CSF manifested sustained and even elevated peripheral neutrophil counts. In our study, $4 \mathrm{~d}$ after administration of cyclophosphamide, i.p. Pseudomonas aeruginosa was administered. Subsequently, there was a significant increase in survival in the CSF-treated group, with a rapid elimination of bacteria, compared with those animals who received no adjuvant CSF therapy and developed profound neutropenia. Additionally, Tanaka et al. (28) similarly demonstrated the protective effects of recombinant murine granulocytemacrophage CSF against $P$. aeruginosa infection in adult mice previously treated with cyclophosphamide. Lastly, Bortolussi et al. (29) examined the protective effects of $\alpha$-, $\beta$-, and $\gamma$-interferon against Listeria monocytogenes in the neonatal rat. Three-d-old neonatal rats were pretreated with i.p. interferon $(\alpha, \beta$, or $\gamma)$ and then challenged with an i.p. or s.c. inoculation of Listeria. Animals receiving at least $10^{5} \mathrm{IU} / \mathrm{kg}$ of prophylactic i.p. interferon had a significant increase in survival against Listeria sepsis.

We and other investigators have examined alternative methods for enhancing human neonatal neutrophil host defense in the treatment of overwhelming bacterial sepsis and neutropenia. Recent clinical studies using adult PMN transfusions as an adjuvant mode of therapy during the treatment of neonatal neutropenia and bacterial sepsis have demonstrated efficacy and an improvement in survival $(30-33)$ but other studies using different methods of granulocyte collection (buffy coat transfusions) have found no additional improvement in survival (34, 35 ). The potential morbidity and difficulty in obtaining leukopheresed granulocytes must be prospectively evaluated and compared with the clinical benefits obtained from adult PMN transfusions in this clinical setting.
Ulich et al. (13) recently demonstrated the myeloproliferative and demarginating effects of rhG-CSF in adult Sprague-Dawley rats. Our study also suggests that i.p. rhG-CSF can modulate and enhance peripheral neurophilia in the neonatal rat and may additionally play a protective role during experimental GBS infection. We have also recently demonstrated that recombinant human CSF may also modulate and enhance neonatal neutrophil physiologic function $(36,37)$. The addition of antibiotics and increased circulating neutrophils or enhanced PMN function appear synergistic against overwhelming bacterial infection presumably by the combination of reduced bacterial growth and enhanced phagocytosis and bacterial killing. Further studies are presently underway to examine the effects after prolonged CSF administration to both preterm and term neonatal rats. Future investigations with the use of these human CSF in enhancing neonatal host defense will need to focus on their enhancement of quantitative deficiencies as well as qualitative deficiencies of neonatal myeloid activity.

Acknowledgments. The authors thank Nancy Franks for expert editorial assistance in the preparation of this manuscript and Dr. Gerald Fisher of Bethesda, MD for providing the GBS for this study.

\section{REFERENCES}

1. Siegel J, McCracken G 1981 Sepsis neonatorum. N Engl J Med 304:642-647

2. Ferrieri P 1988 An overview of neonatal sepsis and the limitations of antimicrobial therapy. In: Session 1 Pathogens and Current Treatment of Infections in the Newborn. Immunopathology Immunotherapy Forum Suppl 1:2

3. Cairo MS 1989 Neonatal neutrophil host defense. Am J Dis Child 143:40-46

4. Cairo MS 1989 Neutrophil transfusions in the treatment of neonatal sepsis. Am J Pediatric Hematol Oncol 11(2):227-234

5. Christensen RD, Macfarlane JL, Taylor NL, Hill HR, Rothstein G 1982 Blood and marrow neutrophils during experimental group B streptococcal infection: quantification of the stem cell, proliferative, storage and circulating pools. Pediatr Res 16:549-553

6. Erdman SH, Christensen RD, Bradley PP, Rothstein G 1982 Supply and release of storage neutrophils: a developmental study. Biol Neonate 41:132137

7. Manroe BL, Rosenfeld CR, Weinberg AG, Browne R 1977 The differential leukocyte count in the assessment and outcome of early-onset neonatal group B streptoccal disease. J Pediatr 91:632-637

8. Gregory J, Hey E 1972 Blood neutrophil response to bacterial infection in the first month of life. Arch Dis Child 47:747-753

9. Christensen RD, Rothstein G 1984 Pre- and postnatal development of granulocyte stem cells (CFUc) in the rat. Pediatr Res 18:599-602

10. Welte KE, Platzer L, Lu L, Gabrilove JL, Levi E, Moore MA 1985 Purification and biochemical characterization of human pluripotent hematopoietic colony stimulating factor. Proc Natl Acad Sci 82:1526-1530

11. Tamura $M$, Hattori $K$, Nomura $H$, Oheda $M$, Kubota N, Imazeki I, Ono $M$ Ueyama Y, Nagata S, Shirafugi N 1987 Induction of neutrophilic granulocytosis in mice by administration of purified human active granulocyte colony-stimulating factor (G-CSF). Biochem Biophys Res Commun 142:454-460

12. Welte K, Bonilla MA, Gillio AP, Boone TC, Potter GK, Gabrilove JL, Moore MA, O'Reilly RJ, Souza LM 1987 Recombinant human granulocyte colonystimulating factor: effects on hematopoiesis in normal and cyclophosphamide treated primates. J Exp Med 165:941-948

13. Ulich TR, Del Castillo J, Souza L 1988 Kinetics and mechanisms of recombinant human granulocyte-colony stimulating factor-induced neutrophilia. Am J Pathology 133(3):630-638

14. Platzer E, Welte K, Gabrilove JL, Lu L, Harris P, Mertelsmann R, Moore MA 1985 Biological activities of human pluripotent hematopoietic colony-stimulating factor on normal and leukemic cells. J Exp Med 162:1788-1801

15. Lopez AF, Nicola NA, Burgess AW, Metcalf D, Battye FL, Sewell WA, Vadas M 1983 Activation of granulocyte cytotoxic function by purified mouse colony-stimulating factors. J Immunol 131:2983-2988

16. Cairo MS 1989 Review of G-CSF and GM-CSF effects on neonatal neutrophil kinetics. Am J Pediatr Hematol Oncol 11(2):238-244

17. Cairo MS, VandeVen C, Mauss, D, Norris K 1989 GM-CSF and G-CSF modulate myloid proliferative and storage pools and induce neutrophilia in the neonatal rat. Pediatr Res 25(4):268A(abstr)

18. Hill HR 1987 Biochemical, structural and functional abnormalities of polymorphonuclear leukocytes in the neonate. Pediatr Res 22:375-382

19. Sieff CA 1987 Hematopoietic growth factors. J Clin Invest 79:1549-1557

20. Souza LM, Boone TC, Gabrilove J, Lari PH, Zsebo KM, Murdock DC, Chazin VR, Bruszewski J, Lu H, Chen KK 1986 Recombinant human granulocyte colony-stimulating factor: effects on normal and leukemic myeloid cells. Science 232:61-65

21. Gabrilove JL, Jakubowski A, Scher H, Sternberg C, Wong G, Grous J, Yagoda 
A, Fain K, Moore MAS, Clarkson B, Oettgen HF, Alton K, Welte K, Souza L 1988 Effect of granulocyte colony-stimulating factor on neutropenia and associated morbidity due to chemotherapy for transitional-cell carcinoma of the urothelium. N Engl J Med 318:14!4-1422

22. Welte K, Bonilla MA, Gillio AP, Boone TC, Potter GK, Gabrilove JL, Moore MA, O'Reilly RJ, Souza LM 1987 Recombinant human granulocyte colonystimulating factor: effects on hematopoiesis in normal and cyclophosphamide-treated primates. J Exp Med 165:941-948

23. Welte K. Bonilla MA, Gillio A 1987 In vivo effects of recombinant human GCSF in therapy induced neutropenias in primates. Exp Hematol 15:72(abstr)

24. Gillio AP, Bonilla MA, Potter GP, Gabrilove JL, O'Reilly RJ, Souza LM, Welte K 1987 Effects of recombinant human granulocyte-colony stimulating factor on hematopoietic reconstitution after autologous bone marrow transplantation in primates. Transplant Proc 6(suppl 7):153-156

25. Bonilla MA Gillio AP, Ruggeiro M, Kernan NA, Brochstein JA, Abboud M, Fumagalli L, Vincent M, Gabrilove JL, Welte K, Souza LM, O'Reilly RJ 1989 Effects of recombinant human granulocyte colony-stimulating factor on neutropenia in patients with congenital agranulocytosis. N Engl J Med 320:1574-1580

26. Hammond WP, Price TH, Souza LM, Dale DC 1989 Treatment of cyclic neutropenia with granulocyte colony-stimulating factor. $\mathrm{N}$ Engl J Med 320:1306-1311

27. Matsumoto M, Matsubara S, Matsuno T, Tamura M, Hattori K, Nomura H, Ono M, Yokota T 1987 Protective effect of human granulocyte colonystimulating factor on microbial infection in neutropenic mice. Infect Immun $55: 2715-2720$

28. Tanaka T, Okamura S, Okada K, Suga A, Shimono N, Ohhara N, Hirota Y, Sawae Y, Niho Y 1989 Protective effect of recombinant murine granulocyte- macrophage colony-stimulating factor against Pseudomonas aeruginosa infection in leukocytopenic mice. Infect Immun 57:1792-1799

29. Bortolussi R, Issekutz T, Burbridge S, Schellekens H 1989 Neonatal host defense mechanisms against Listeria monocytogenes infection: The role of lipopolysaccharides and interferons. Pediatr Res 25:311-315

30. Cairo MS, Rucker R, Bennetts GA, Hicks D, Worcester C, Amlie R, Johnson S, Katz J 1984 Improved survival of newborns receiving leukocyte transfusion for sepsis. Pediatrics 74:887-892

31. Cairo MS, Worcester C, Rucker R, Bennetts GA, Amlie R, Perkin R, Anas N, Hicks D 1987 Role of circulating complement and polymorphonuclear leukocyte transfusion in treatment and outcome in critically ill neonates with sepsis. J Pediatr 110:935-941

32. Christensen RD, Rothstein G, Anstall HB, Bybee B 1982 Granulocyte transfusions in neonates with bacterial infection, neutropenia, and depletion of mature marrow neutrophils. Pediatrics 70:1-6

33. Laurenti F, Ferro R, Isacchi $G$, Paners A, Savignoni $G$, Malagnino F, Palermo $D$, Mandelli F, Bucci G 1981 Polymorphonuclear leukocyte transfusion for the treatment of sepsis in the newborn infant. J Pediatr 98:118-122

34. Baley JE, Stork EK, Warkentin PI, Shurin, SB 1987 Buffy coat transfusions in neutropenic neonates with presumed sepsis: a prospective, randomized trial. Pediatrics 80:712-720

35. Wheeler JG, Chauvenet AR, Johnson CA, Block SMG, Dillard R, Abramson JS 1987 Buffy coat transfusions in neonates with sepsis and neutrophil storage pool depletion. Pediatrics 79:422-425

36. Cairo MS, Mauss D, Suen Y, VandeVen CJ, Sender L 1989 Modulation of neonatal PMN mobility: adherence, aggregation and MO-1 receptor expression by rh-GM-CSF. Pediatr Res 25(4):148A(abstr)

37. Cairo MS, VandeVen C, Toy C, Mauss D, Sender L 1989 Recombinant human granulocyte-macrophage colony stimulating factor primes neonatal granulocytes for enhanced oxidative metabolism and chemotaxis. Pediatr Res 26(5):395-399 